\title{
Compact Microwave Power Limiter with HTSC Element
}

\author{
Ilya V. Govorun* \\ Alexsander A. Leksikov ${ }^{\dagger}$ \\ Kirensky Institute of Physics SB RAS \\ Akademgorodok, 50, Krasnoyarsk, 660036 \\ Russia \\ Alexey M. Serhantov $\ddagger$ \\ Institute of Engineering Physics and Radio Electronics \\ Siberian Federal University \\ Svobodny, 79, Krasnoyarsk, 660041
}

Russia

Received 13.09.2016, received in revised form 09.01.2017, accepted 09.08.2017

A design of microwave power limiter having a structure of three-pole microstrip filter is developed. In the device outer resonators are coupled through an inner resonator containing high-temperature superconducting film. Prototype of the device with central frequency $7.9 \mathrm{GHz}$ and relative bandwidth $9 \%$ has insertion loss $1.5 \mathrm{~dB}$ in the open state and suppress a signal not less $30 \mathrm{~dB}$ in the limitation state.

Keywords: power limiter, microwave, damping pole, microstripe structure, HTSC.

DOI: 10.17516/1997-1397-2018-11-1-35-39.

Important part of any reception radar system is power limiter. It is function is to protect input circuits of system from external high-power microwave pulse. Important electric characteristics of limiters are the next: switching time, level of power limitation (attenuation in the limitation mode), insertion loss in pass state mode. Vacuum electron limiter meets all these requirements [1]. However, its operation demands constant magnetic field, the last circumstance leads to increase in dimensions and weight. It is known that time of phase transition of hightemperature superconductors (HTSC) from low-loss superconducting to high-loss normal state has a very small value $\left(<10^{-12} \mathrm{~s}\right)$ [2]. This circumstance is used by developers for designing power limiters on the basis of HTSC. Such devices are made in the form of transmission line matched with a path and made of HTSC film (most often microstrip or co-planar) [3,4]. In the mode of "weak" signal the limiter has insignificant insertion losses. In the mode of "high-power" signal the guided microwaves are followed by microwave (MW) currents in the line and their density exceeds critical threshold for HTSC material. The HTSC-line passes from the superconducting to normal state. As a result ohmic losses increase and limitation of input power occurs. It should be noted almost all power falling to the input of such device will be absorbed and dissipate in the form of heat. As thickness of a HTSC film is about hundreds of nanometers, it is obvious that the absorptive principle of operation of such devices will lead to evaporation of the film.

This shortcoming is absent in HTSC power limiters designed on the basis of the new concept $[5,6]$, where limitation occurs due to reflection, not absorption. Such device has a structure

\footnotetext{
*govorun-ilya@mail.ru

†leksikov@iph.krasn.ru

${ }^{\ddagger}$ cubicus@mail.ru

(c) Siberian Federal University. All rights reserved
} 
of a three-resonator bandpass microstrip filter. In the structure strip conductors of the outer resonators are completely made of copper, and the third one (inner) has a gap in its central part in which HTSC-element is placed. Noted, the total coupling coefficient defines a degree of electromagnetic interaction between resonators at resonant frequency and consequently also bandwidth. Input and output resonators in the absence of the inner one do not interact with each other because the total coupling coefficient between them is equal zero. This phenomenon becomes possible only with a special topology of resonators and a certain gap between them. In this case, the module of inductive coupling coefficient becomes equal to the module of capacitive coupling coefficient, and due to their opposite signs at frequencies of the passband a damping pole appears. It is necessary to notice that in this case almost all input power reflects from the input of such power limiter at a frequency of the damping pole. Outer resonators interact with the help of the inner resonator. Its sizes are designed in such a way that its resonant frequency is equal to frequencies of the outer resonators. As a result the three-resonator bandpass filter with small insertion losses is formed. If to the input of such device the signal comes and its power exceeds a critical value, the HTSC-element passes into a high-resistive state and quality factor of the inner resonator falls sharply. Thus, the inner resonator abandons to connect the outer ones and a limitation of the MW power occurs. It is worth noticing that in such devices the limitation comes due to reflection of power from the input.

The trend to miniaturization and increase in functionality of the microwave receiver equipment demands from the developers to search the ways of reduction of devices dimensions. Using quarter-wavelenght microstrip resonators for creation of the microwave power limiters is one of simplest ways to reduce their sizes. It is known [7] that for a two-resonator structure based on quarter-wavelength stepped-impedance microstrip resonators it is possible to choose such distance between them that the total coupling coefficient be equal zero at a frequency of the passband. The microwave power limiter, whose outer resonators are quarter-wavelenght and stepped-impedance, is presented in this work.

The considered structure (Fig. 1 left) consists of three microstrip resonators on substrate 1, the bottom surface 2 of which is completely metal-coated. At the same time outer resonators 3 are stepped-impedance, and their high-impedance parts are grounded and they are made of copper. The central resonator is half-wave, in its middle part there is a gap where HTSCelement is placed. It is known, in the central part of the half-wave resonator there is the area of a antinodes of the microwave current at a resonant frequency. That resonator is a composite one, it consists of two rectangular copper patches 4 and HTSC-element having the dumbbell form 7. It is necessary to notice, on the wide parts of HTSC-element silver thin layer $(0.15 \mu \mathrm{m})$ is deposited. Due to this the patches 4 and HTSC-element 7 have galvanic contact with a help copper foil 5. HTSC-element is fulfilled on a separate substrate 6 . For the design consisting of a pair such resonators at a certain distance between them the total coupling coefficient becomes equal zero and at a frequency in the passband a damping pole appears. As mentioned above, this is caused by the fact that in such two resonators structure inductive and capacitive coupling coefficients are closed to each other on the magnitude, but have different signs (work in an antiphase). The inner resonator is half-wave, its resonant frequency is equal to the frequencies of the outer quarter-wave resonators.

Using the topology of the conductors shown in (Fig. 1 right), a prototype power limiter was manufactured with the following design parameters: the alumina substrate with thickness of $0.5 \mathrm{~mm}(\varepsilon=10.6), l_{r}=2.25 \mathrm{~mm}, l_{e}=1.1 \mathrm{~mm}, W_{e}=1.8 \mathrm{~mm}, W_{i}=0.5 \mathrm{~mm}, S_{1}=0.3 \mathrm{~mm}$, $S_{2}=0.25 \mathrm{~mm}$. The sizes of the low-impedance and high-impedance parts of the HTSC element 
were $1 \times 0.6 \mathrm{~mm}^{2}$ and $0.9 \times 0.1 \mathrm{~mm}^{2}$, respectively. The sizes of the patch 4 were $1.7 \times 0.65 \mathrm{~mm}^{2}$. Locations of tapping point were chosen from the condition of the maximum return losses in the passband to be $14 \mathrm{~dB}$. It should be noted that the dimensions of the device were $6.3 \times 4.5 \mathrm{~mm}^{2}$. In comparison with the design investigated earlier [8] the constriction sizes decreased almost twice. The $\mathrm{YBaCuO}$ HTSC film having thickness $150 \mathrm{~nm}$ was deposited on the $\mathrm{NdGaO}_{3} 0.5 \mathrm{~mm}$ substrate. The surface resistance of the film in the normal state was $10 \mathrm{Ohm} / \square$. The HTSC films were produced by technology described elsewhere [9]. The device was cooled with liquid nitrogen.

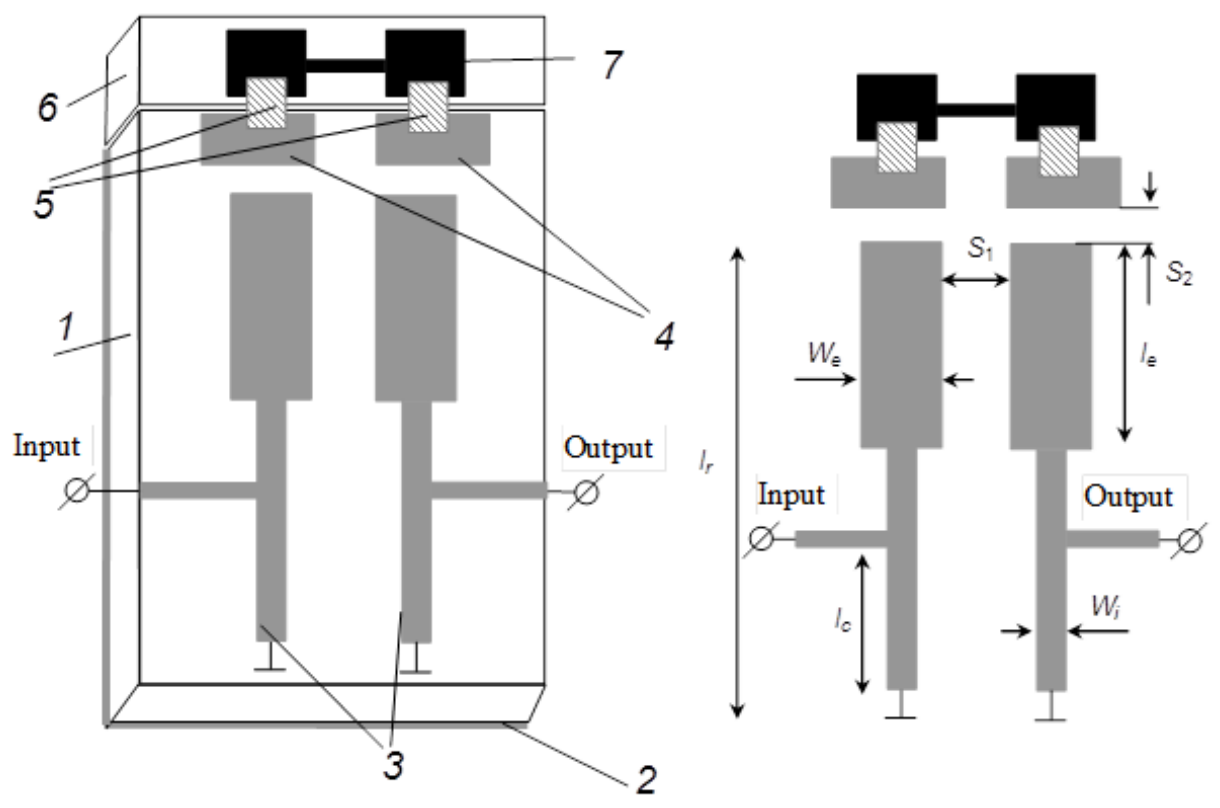

Fig. 1. Left: design of the microstrip power limiter. Right: conductor's pattern and structure parameters of the designed and fabricated device

Width of a working passband of the power limiter is defined by $S_{2}$, the gap between the open ends of the outer resonators, and the copper patches of the inner composite resonator. Increase in distance $S_{2}$ leads to reduction of interaction between outer resonators with each other through inner one, and, as a result, bandwidth decreases. As researches showed earlier [5] for such limiters reduction of bandwidth leads to increasing attenuation of a signal in the limitation mode. That is a positive factor for power limiter. Thus, on designing a limiter it is necessary to choose width of a passband as minimum as possible.

Fig. 2 on the left shows the frequency dependences of the transmission coefficient of the simulated and developed prototype of the device. The solid curves here show the results of electromagnetic simulating using the program Sonnet Lite, and the dashed curves show experimental results. It can be seen that when the HTSC-element is in the superconducting state, which corresponds to the on-state of the device, it has the passband with fractional width of about $9 \%$ and the central frequency of about $7.9 \mathrm{GHz}$; in this case, transmission losses in the passband are only $1.5 \mathrm{~dB}$. When the HTSC-element is in its normal state corresponding to the off-state, the transmission coefficient at the working frequencies decreases by about $30 \mathrm{~dB}$. One can see the experimental data are in good agreement with the electromagnetic simulation. 
For more complete description of the power limiter operation, the measurement of output power versus input power, so-called transfer characteristic, was carried out. The result is presented graphically in (Fig. 2 right). It is seen the device passes into the limitation mode at the input power about $90 \mathrm{~mW}$, and the power leakage level does not exceed $36 \mathrm{~mW}$ when the input power is $44 \mathrm{~W}$. In the interval of input power $90 \ldots 446 \mathrm{~mW}(19.5 \ldots 26.5 \mathrm{dBm})$ reverse motion of the transfer characteristic is observed. Obviously, it is connected to the HTSC-element passes to the normal state partially in this interval of input power. On further increasing in input power the main part of HTSC-element switches into high-resistance state and the output power growths again.
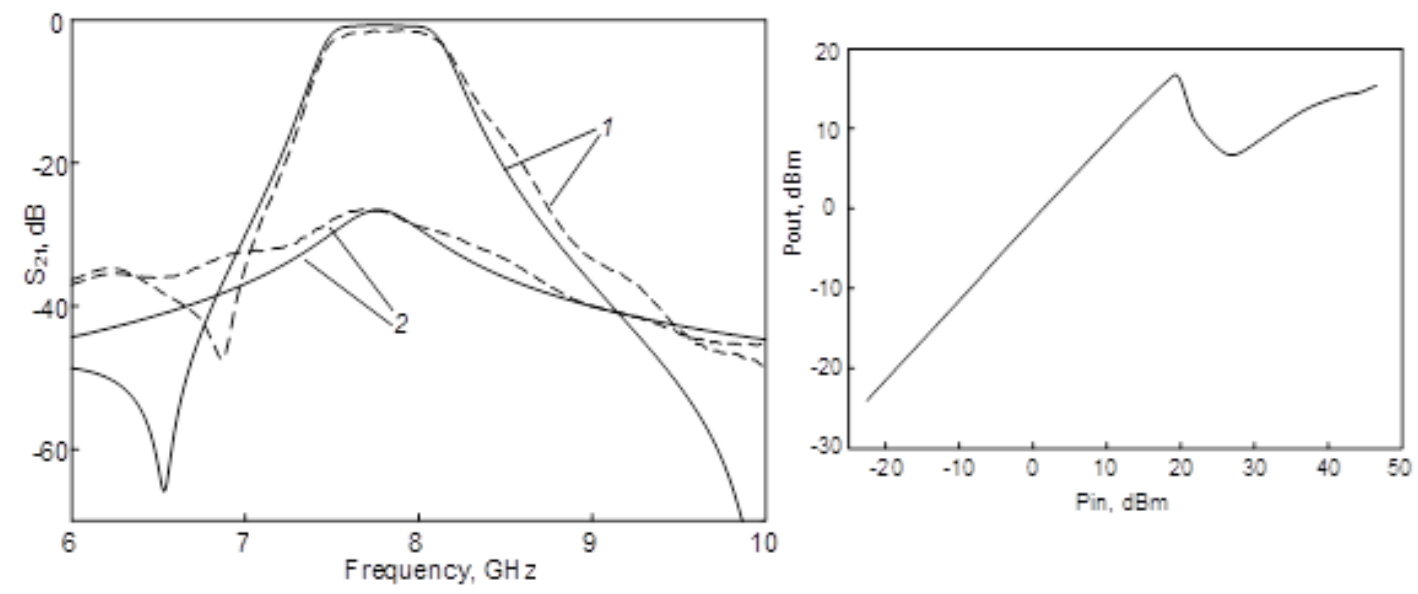

Fig. 2. Left: frequency response of the power limiter in cases when the HTSC element is in the superconducting (1) and normal state (2). The solid curves are for the results of electromagnetic simulation, the dashed curves are experimental data. Right: transfer characteristics of the fabricated device

A new compact structure of microwave power limiter is presented. The device consists of two microstrip quarter-wave irregular resonators and the third composite resonator with HTSCelement. The prototype of the limiter has operation passband $9 \%$ with central frequency $7.9 \mathrm{GHz}$. The transfer characteristics of the device were investigated in the case of microwave power level up to $44 \mathrm{~W}$.

The work was supported by the Ministry of Education and Science of the Russian Federation, grant CI-3036.2016.3. of the President of the Russian Federation for State Support of Young Russian Scientists.

\section{References}

[1] Yu.A.Budzinskiy, S.V.Bykovskiy, V.E.Kotov, O.A.Savrukhin, On the increase of the frequency band of cyclotron protective device, CriMiCo'2014, Sevastopol, Russia, 2014.

[2] A.T.Findikoglu, D.W.Reagor, K.O.Rasmussen, A.R.Bishop, N.Gronbech-Jensen, Q. X.Jia, Y.Fan, C.Kwon, L.A.Ostrovsky, Electrodynamic properties of coplanar waveguides made from high-temperature superconducting $\mathrm{YBaCuO}$ electrodes on nonlinear dielectric $\mathrm{SrTiO}_{3}$ substrates, Journal of Applied Physics, 3(1999), 1558-1568. 
[3] J.C.Booth, D.A.Rudman, R.H.Ono, Self-Attenuating Superconducting Transmission Line for Use as a Microwave Power Limiter, IEEE Trans. on Appl. Supercond, 2(2003), 305-310.

[4] A.A.Kalenyuk, Nonlinear microwave response of a superconducting YBa2Cu3O7 microstrip transmission line with a constriction, Low Temperature Physics, 2(2009), 105-111.

[5] B.A.Belyaev, I.V.Govorun, A.A.Leksikov, A.M.Serzhantov, Receiver Protecting Device Based on Microstrip Structure with High-Temperature Superconductor Film, Technical Physics Letters, 3(2012), 211-214.

[6] B.A.Belyaev, I.V.Govorun, A.A.Leksikov, A.M.Serzhantov, Investigation of the special features of the coupling coefficient microstrip asymmetric hairpin resonators at frequencies of the second passband, Russian Physics Journal, 10(2013), 1215-1221.

[7] B.A.Belyaev, A.M.Serzhantov, Features coupling coefficients of quartewave microstrip resonators, Journal of communications technology and electronics, 3(2004), 275-281.

[8] B.A.Belyaev, I.V.Govorun, A.A.Leksikov, A.M.Serzhantov, An.A.Leksikov, Reflective power limiter for X-band with HTSC Switching element, IEEE Transactions on applied superconductivity, $\mathbf{7}(2016), 1-6$.

[9] A.V.Smirnov, M.S.Karmantsov, K.V.Smirnov, Y.B.Vakhtomin, M.A.Tarkhov, D.V.Masterov, S.A.Pavlov, A.E.Parafin, Terahertz response of thin-film YBCO bolometers, Technical Physics, 12(2012), 1716-1719.

\title{
Компактный ограничитель СВЧ-мощности с ВТСП-элементом
}

\author{
Илья В. Говорун \\ Александр А. Лексиков \\ Институт физики им. Л. В. Киренского СО РАН \\ Академгородок, 50/38, Красноярск, 660036 \\ Россия \\ Алексей М. Сержантов \\ Институт инженерной физики и радиоэлектроники \\ Сибирский федеральный университет \\ Свободный, 79, Красноярск, 660041 \\ Россия
}

\begin{abstract}
Была разработана конструкиия ограничителя СВЧ-мощности, имеющал структуру трехзвенного микрополоскового фильтра. В устройстве внешние резонаторы связаны посредством внутреннего, содержащего ВТСП-пленку. Макет устройства с центральной частотой 7.9 ГГи и относительной полосой пропускания $9 \%$ имеет потери 1.5 дБ в открытом состоянии и не менее 30 дБ ослабления в режиме ограничения.
\end{abstract}

Ключевые слова: ограничитель мощности, СВЧ, полюс затухания, микрополосковая структура, ВТСП. 